\title{
Incidental Lexicon Acquisition through Playful Interaction
}

\author{
http://dx.doi.org/10.3991/ijet.v10i1.4156 \\ L.W. Ansteeg \\ NHTV University, Breda, Netherlands
}

\begin{abstract}
This paper presents an educational game which aids learners with foreign lexicon acquisition while entertaining them at the same time. An overview over existing language learning tools is given, and a general platform for educational games for second language acquisition (SLA) is described. It introduces a specific prototype video game which teaches Italian vocabulary to the user. The application puts learning at the core of its game mechanics and combines it with a narrative and role-playing elements. In a user study, the game is compared to two other learning methods with focus on long term retention of vocabulary and enjoyment of the exercise. The game is found to perform within $10 \%$ of the efficiency of pure vocabulary learning exercises, while being considerably more enjoyable to the user.
\end{abstract}

Index Terms-Game Based Learning, Lexicon Acquisition, Second Language Acquisition, Serious Games

\section{INTRODUCTION}

Many people attempt to learn foreign languages over the course of their lives, but only few ever achieve a level of mastery necessary for fluent conversation [1].

There are numerous reasons for starting to learn a language, such as cultural integration, learning as part of a school curriculum, interest in foreign media, travel, etc. [2]. Certain motivations for learning result in a higher chance of success; as one might presume, students who are intrinsically motivated to learn a language fare much better than those who are forced to, or motivated extrinsically [3]. Some people may stop learning a language because they are no longer interested in it; however, many would like to learn a language, but find the process of learning complicated grammars and thousands of words too bothersome. As the success of learning a foreign language depends largely on the student's motivation (Ushida, 2005; Gardner, 2000), it can be assumed that a more intrinsically rewarding method of learning languages would lead a higher percentage of language learners to success. One way to achieve this could be through serious games, which can transform problems into intrinsically enjoyable pastimes [4]. A serious game which teaches the user a foreign language, while being fun at the same time, could solve the issue of lacking motivation and thus help a higher percentage of language learners reach fluency.

Both academics and industry have attempted to create such games, which will be discussed in the next section. However, most games either lack the attractiveness of commercial games, or do not effectively teach the target language.

This paper will introduce a game which attempts to combine the intrinsically fun aspects of video games with effective language learning. A prototype of that game has been tested in a longitudinal study for user enjoyment and long term retention of vocabulary. Finally, the usefulness of the game will be evaluated, and future improvements will be suggested.

\section{EXISTING EDUCATIONAL GAMES}

Numerous attempts have been made at creating effective educational games, but only a few have tackled language learning specifically. Most attempts can be categorized into one of three groups.

\section{A. Poorly Merged Games}

A number of games exist which use gameplay as a reward for learning, where learning itself happens outside of gameplay. Figure 1 displays an extreme example ${ }^{1}$ : Whatever amazing game starts when pressing "Play game" - it will not change the fact that the user had to learn the words in a boring and uninspiring fashion.

Other games in this category transition between learning and gameplay frequently to keep up the illusion that learning is the game. The game displayed in Figure 2, for example, is a version of the game "Shell Shock", where the player has to answer a question before every turn to be allowed to continue playing ${ }^{2}$. This interrupts the game which is fun with exercises which are not, and the player hardly focuses on the target language.

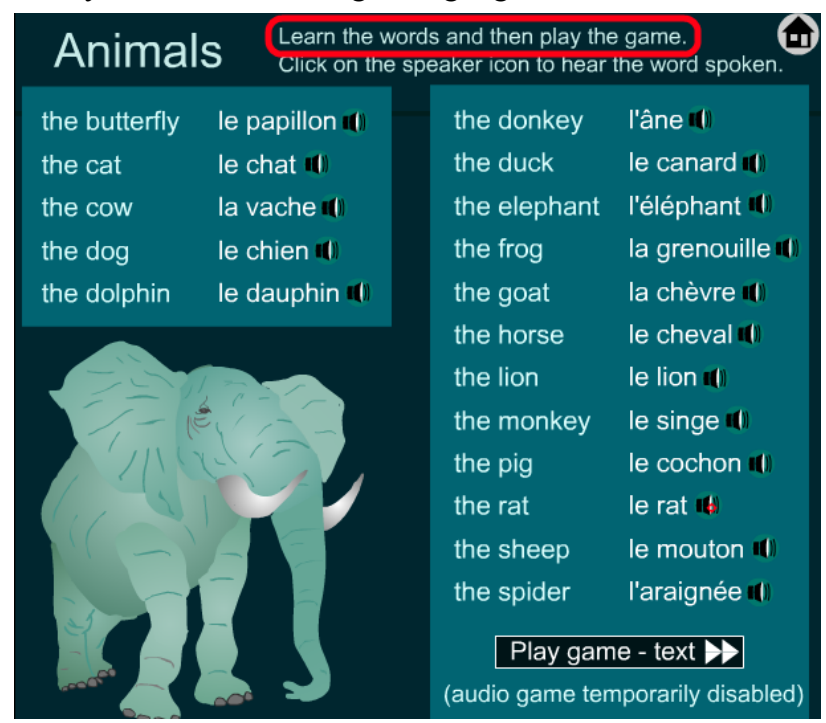

Figure 1. Example of a poor merge between game and exercise

\footnotetext{
${ }^{1}$ http://www.digitaldialects.com/French/Animals simp.htm 2 http://www.123teachme.com/games/tank/category/adjectives
} 


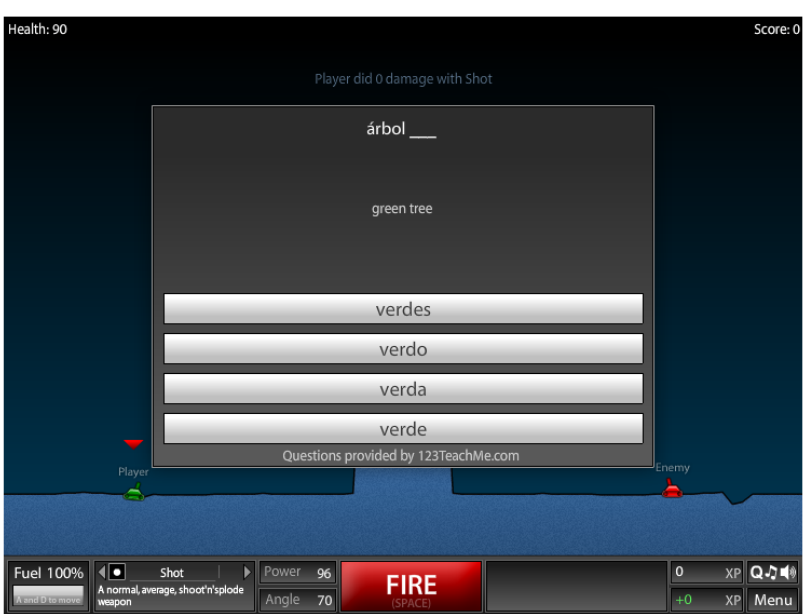

Figure 2. Example of interrupting gameplay

\section{(1) $00000000002 \quad 1,575$ energy points}

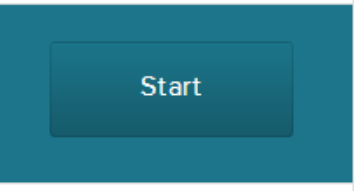

WEEKLY GOALS

Practice skills: $0 / 5$ Mastery challenges: $0 / 5$ raster chalenges: $0 / 50$

Practice

\section{MISSION PROGRESS}

Figure 3. Example of badges and progress bars

\section{B. Gamification/Skinner Boxing}

Gamification is the process of applying game mechanics to non-game subjects [5]. The aim is to make serious tasks as engaging as playing a game, where learning is stimulated in a fun environment.

An example is Khan Academy ${ }^{3}$, which offers multiple courses packed with points, badges, achievements, etc.

In reality though, gamified products rarely reach the entertainment value of games, nor do they stimulate the same level of engagement. Usually, gamification takes a complete process or product, and adds operant conditioning in the form of points, badges, visual rewards, competition and level progression (Figure 3). This does help motivate the user to keep playing and to return to the product regularly; however, only extrinsic motivation is achieved, and the act of using the product itself is still as tedious as before. None of the intrinsically fun parts of games are transferred. It is certainly a step in the right direction, but reaches only part of the potential of educational games.

\section{Playful Interaction}

There are a few applications which use language learning as the gameplay itself, rather than attaching it to an existing game. One of them is "Word War", a game created to teach Mandarin Chinese vocabulary to students. It was compared to the traditional methods of using flash

\footnotetext{
${ }^{3}$ http://www.khanacademy.org
}

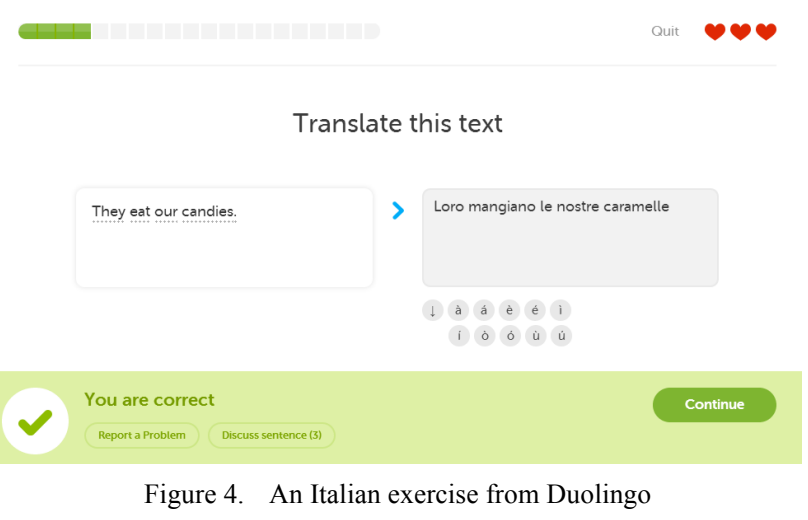

cards for vocabulary acquisition, and not only was perceived by users as more enjoyable, but also performed on par with flash cards in terms of long term retention of the learned words [6]. Unfortunately, most such games are of poor production quality and would not hold against commercial products in terms of entertainment [7].

An excellent example from this category is Duolingo ${ }^{4}$, a website and mobile application which is hardly recognizable as a game (Figure 4). It uses a bare minimum of extrinsic motivation, and instead makes the learning itself engaging through a good difficulty curve, immediate feedback, and a variety of exercises. In a study of Spanish learners using Duolingo, it was found that 34 hours of using the app prepared users as well as one college semester of Spanish in the US [8].

\section{Desireable GAME FeAtures.}

This playful interaction combined with a narrative which will keep the player engaged to the point of continued playing is the goal of the proposed game. The next section will describe a general outline of criteria which such a game would need to fulfil.

A complete learning solution should be able to lead the player from no knowledge of the language to a state where they can read, write, listen to and talk in the target language. It thus has to teach both the grammar and lexicon to the learner. At the same time, the game must keep the player engaged and interested, so that each play session is enjoyable, and motivation to complete the studies is added.

\section{LEXICON ACQUISITION}

Second language lexicon acquisition is the process of learning a collection of lexical entries which are part of the foreign language. These entries, notably, are not simply words but also attributes associated with it such as pronunciation, meaning, use, etc.

It is thus not enough to simply learn words without knowing the context in which to use them, or the rules governing their use. A lexical entry, or lexeme, includes amongst others (Hulstijn, 2001):

- Morphonology

- Orthography

- Prosody

- Semantics

- Pragmatics 


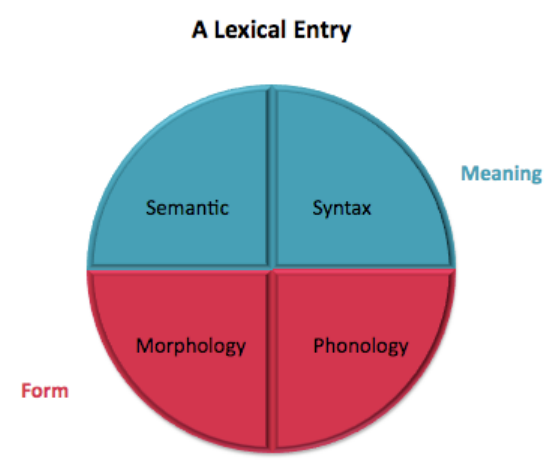

Figure 5. A lexical entry (Adaptation based on Levelt, 1989)

\section{A. Morphonology}

To completely teach a lexeme, the game must cover all morphological forms of that entry. To use all of them in gameplay, the user must either be prompted to derive inflected word forms himself depending on context, or the card must randomly assume one morphological form and the user puts it into the suitable context.

The word "stem" could be taught individually as a oneto-one translation of the corresponding English lexeme, but in order to properly teach the morphological changes depending on context, the lexemes should be used in sentence-structure. One way to achieve this could be prompting the player to write entire sentences rather than simply translations of single lexemes. Using incorrect inflection could result in a lowered score, though the user could still get positive feedback for what they did correctly.

\section{B. Orthography}

Orthography is perhaps the simplest and most selfexplanatory aspect of the game. All words are conveyed in written form and thus associated with their correct orthography. To effectively link the orthography to phonetics, words should be read aloud, and irregularities of the language must be pointed out.

\section{Prosody}

The rhythm, stress and intonations of words in context are very difficult to convey through a generative learning program. While ideally sentences would be read back to the user with correct prosody according to context, this is a technical impossibility at this time. Rules of prosody can be explained in separate specific lessons, but are difficult to integrate into the core gameplay since the computer can neither generate nor evaluate this aspect. Research in this field is progressing, and future iterations may be able to include appropriate features (Al Moubayed, 2009; van Santen et al., 2003)

\section{Semantics}

Semantics need to context to be properly conveyed. For lexemes which denote things (e.g. nouns), the basic semantics are easily conveyed through pictures, translations, etc. The semantics of lexemes denoting actions or attributes are more difficult to convey. Ideally a game should use them in a metaphorical way which resembles their meaning in the context of gameplay.

To properly teach the semantics of different lexemes, a game might need different gameplay at different stages of the game, so that all words can be introduced in a context where they make sense.

\section{E. Pragmatics}

Pragmatics should be implemented through the use of multiple simultaneous media channels. When a lexeme is presented, it should be accompanied by pictures and voice-overs, animations, and other context-providing clues. While this might not be the most accurate representation of real world pragmatics, it allows the user to overcome ambiguity within the game. Situations which allow for multiple interpretations should in any case accept all possible answers as correct.

\section{GRAMMAR}

Traditionally, grammar in second language acquisition (SLA) is taught by explaining a rule, and then having the learner practice it on examples until the rule is internalized.

This is in opposition to how children acquire languages: They are simply exposed to so many instances of the grammatical rule in context, that they internalize the rule without explicit knowledge of it. Some teaching methods, like Duolingo, adopted this approach. They integrate new grammatical rules into exercises which the user already knows, and have the player memorize a number of instances until they themselves generalize a rule.

It is unclear which method is more effective in SLA [10], but for any playful purpose the integrated approach would be more desirable. Explicit grammar lessons interrupt the game flow, and are seen a boring necessity to continue. Educational games should keep these interruptions to a minimum, and try to convey as much information through gameplay itself.

\section{A. Interlanguage}

Everything the leaner knows, or thinks they know, about the target language, is referred to as the interlanguage [11]. The interlanguage continuum is essentially a completely new grammar which is created by the learner, and constantly changes as the learner attempts to construct the grammar of the target language [12].

An educational game can track every mistake the player makes, and can thus calculate a fairly accurate account of what the interlanguage encompasses. All sections of the game should have a variable length, so that players will not move past grammatical rules which they have not fully mastered.

If the game registers the player's native language, predictions about common errors can be made even before they start playing, and concepts which are intuitive to speakers of similar languages can be explained in more detail to those who do not have the prior knowledge.

\section{B. Construction of Sentences}

Grammar, and the context-sensitive aspects of lexemes, will be best taught if exercises include entire sentences rather than single words. Unfortunately, it is much more difficult to procedurally generate such exercises, and even more difficult to correct them.

The generation of such exercises could be done by creating exercise patterns which switch out a number of words. Lexemes could then be tagged according to which 
exercises they can be used in, and the generator randomly picks valid words which are known to the player.

Correcting the answers to such generated problems is more difficult. Players must be allowed some freedom in how they structure their answer, to encourage creative and autonomous thinking in the interlanguage. However, it is not easy to create a parser which understands synonyms, alternative word order, etc. A balance must be struck when designing the tasks of the player, so that the possible answers are manageable.

\section{Methodology}

Any educational game should be built on a basic understanding of cognitive sciences, and a specific knowledge of applied linguistics. Every part of the game should be designed in a way that stimulates learning as much as possible.

\section{A. Multisensory output}

Information is best embraced when receiving it through multiple senses [13]. Ideally a game will use multiple channels of information at once, or alternate between them. (Such as having a voice pronounce a word to the user while presenting the written from).

Even when the game cannot meaningfully integrate all aspects of a language into the gameplay, it may still help to add abstract information. Visual and audio cues should be combined whenever possible. If technology ever allows to effectively convey additional sensory information, it might further help to increase brain stimulation.

\section{B. Spaced Repetition}

In order for information to be remembered in the long term, it must be recalled at given intervals. A game has a unique advantage here, as it can track precisely when the user has last used each word.

From the time a word is first introduced to user to the time it is considered mastered, a spaced repetition system combining the Pimsleur method [14] with the Leitner system [15] should be used.

Once the user acquired a new lexeme, their mastery of this lexeme starts at 0 . Reaching a mastery of 1 would assume perfect knowledge of all aspects of the lexeme. The mastery of a lexeme is the average of the mastery of all sub-aspects of this lexeme, each having an individual mastery rating.

Correctly using any lexeme in any exercise increases the mastery rating of the appropriate aspects of the lexeme. Using it incorrectly reduces mastery. The lexeme is presented less frequently to the user as the mastery level rises, ensuring that complete mastery can only be achieved after a long period of time and not through short-term retention.

Unlike the Leitner system, failing to use a lexeme correctly should not reset the mastery to 0 , but rather decreases it by a variable amount. Between play sessions, mastery should decay automatically for any word not completely mastered, so that players who return after a pause will first review words they might have forgotten before moving on to new ones.

\section{Operant conditioning}

The lesson from gamification is that, while it may not be enough in itself, it does help tremendously in extrinsically motivating the player. Rewarding the player a little after every action, if only with a positive sound effect or small animation, supplements the core gameplay and drives the player to continue.

Creating daily challenges which result in high amounts of ingame rewards, will push the players to return to the game regularly. Visual representations of the progress made so far can remind the player that what they do is meaningful.

\section{COMPLETED PROTOTYPE}

For the purpose of this paper, a simple game prototype was created. To keep a reasonable scope, the prototype only teaches vocabulary, specifically only orthography and phonetics of the lexicon, which is a large and complex problem in itself.

In the game, the target language (Italian) is the language of magic, and the player must learn the words in order to perform magic spells with them. As a wizard apprentice, the player goes on a quest to master the magical language (Figure 6).

The player learns four different abilities, which all represent a different learning method. Using those abilities, the player can defeat opponents and progress in the game. Some gameplay conventions are borrowed from the roleplaying genre (Figure 7).

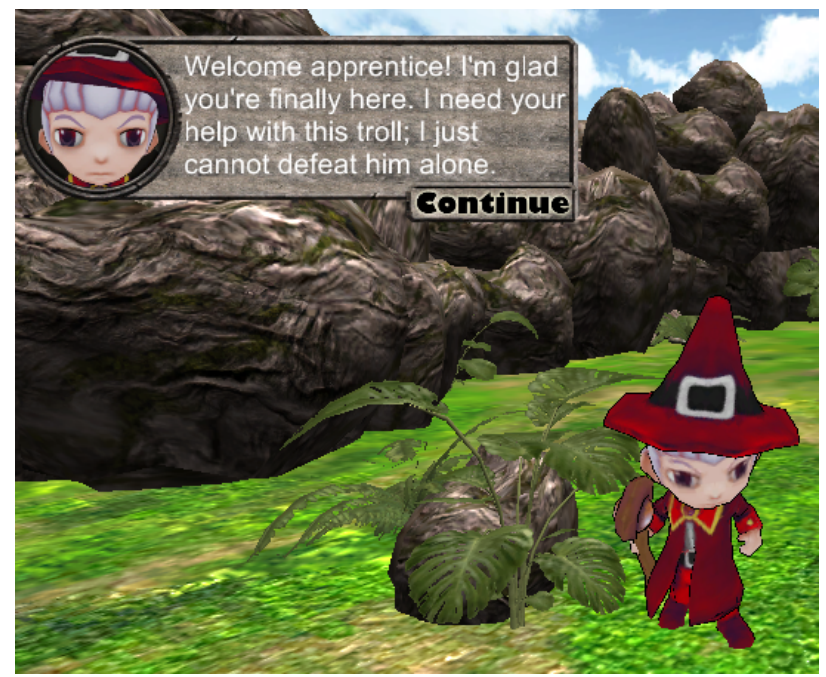

Figure 6.



Figure 7. 
The four abilities are:

- Pick correct translation from three choices

- Quickly translate the word while the correct translation is slowly revealed

- Write down the word after hearing it

- Translate from English to the target language

Each of these abilities works with all lexemes which the player has to learn. The player can choose which ability they want to use next, but the lexical entry is chosen depending on a spaced repetition algorithm. In this prototype, the algorithm is extremely simplified:

$$
\begin{aligned}
& W_{n}=1-M_{n} \\
& P_{n}=\frac{W_{n}}{\sum_{i=1}^{n} W_{i}}
\end{aligned}
$$

Where for lexeme $n: W_{n}$ is the weight, $M_{n}$ the mastery, and $\mathrm{P}_{\mathrm{n}}$ the probability to be chosen next.

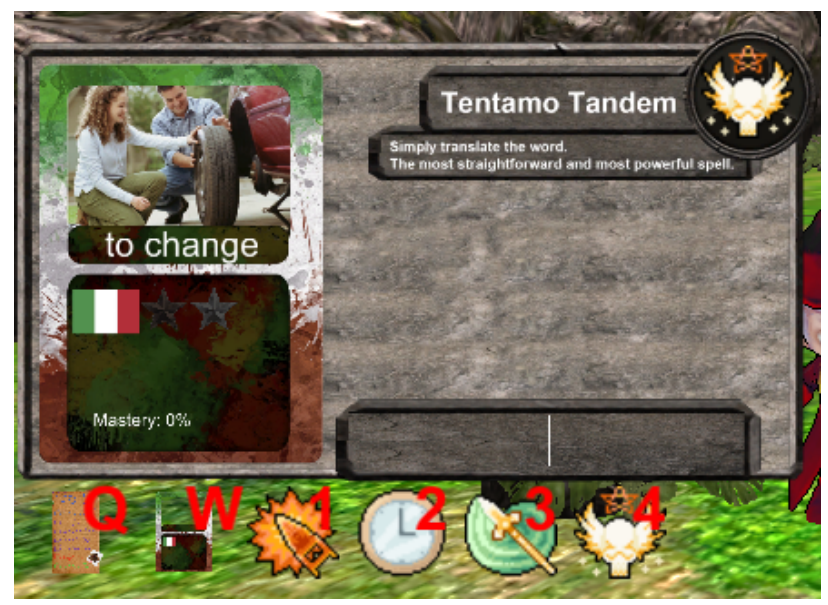

Figure 8.

The player practices on target dummies until they have learned the four abilities, and then moves on to fight an opponent. As the player masters some of the words, new ones are unlocked.

Lexemes in the game are represented as collectible cards, to tap into the human desire of completing collections [16]. At all times the player can check their progress, to see how far they have come.

The game was designed to have the player actively learning as much as possible. As such, dialogue between gameplay is short, and the choices the player makes are directly related to the study material.

Learning vocabulary is the gameplay itself: The players do not ever have to study before they can continue, but rather learn while playing.

The spaced repetition of lexemes creates a comfortable but challenging flow to the player: New words are not introduced if the player still struggles with the ones they have, yet they equally are not allowed to continue using words after having already mastered them.

\section{USER STUDY}

The user study verified whether the game fulfills its goal: Teaching effectively while being entertaining at the same time. For that purpose, the game prototype was compared to two other methods for lexicon acquisition: Flash cards and the website memrise.com.

The three different learning systems were compared in a longitudinal study over the span of three weeks. The participants attempted to learn 27 Italian words (W), grouped into three sets:

\begin{tabular}{|l|l|l|l|}
\hline & \multicolumn{1}{|c|}{$\mathbf{W}_{\mathbf{1}}$} & \multicolumn{1}{c|}{$\mathbf{W}_{\mathbf{2}}$} & \multicolumn{1}{c|}{$\mathbf{W}_{\mathbf{3}}$} \\
\hline Noun & $\begin{array}{l}\text { la mattina } \\
\text { la scuola } \\
\text { il fratello }\end{array}$ & $\begin{array}{l}\text { la sorella } \\
\text { la spiaggia } \\
\text { il monte }\end{array}$ & $\begin{array}{l}\text { l'isola } \\
\text { il progetto } \\
\text { la barca }\end{array}$ \\
\hline Verb & $\begin{array}{l}\text { suonare } \\
\text { regalare } \\
\text { cambiare }\end{array}$ & $\begin{array}{l}\text { amare } \\
\text { spedire } \\
\text { accettare }\end{array}$ & $\begin{array}{l}\text { piovere } \\
\text { chiedere } \\
\text { evitare }\end{array}$ \\
\hline Adjective & $\begin{array}{l}\text { meglio } \\
\text { facile } \\
\text { divorziato }\end{array}$ & $\begin{array}{l}\text { pulito } \\
\text { matto } \\
\text { autoritario }\end{array}$ & $\begin{array}{l}\text { peggio } \\
\text { chiuso } \\
\text { diretto }\end{array}$ \\
\hline
\end{tabular}

In the first two sessions, participants used each method for 10 minutes, and completed a test of the learned words immediately after. In all three sessions all 27 words were tested in the beginning to test long term retention.

The 12 participants were put in one of three groups $\mathrm{g}=$ $\{\mathrm{A}, \mathrm{B}, \mathrm{C}\}$. Each group would use all three methods and learn all 27 words, but each group had a different set of words through the same method. Each group also used the methods in a different order, so that potential advantages gained through sequence or easier to learn words would not affect the rating of any learning method.

\begin{tabular}{|c|c|c|c|c|c|c|c|}
\hline \multicolumn{8}{|c|}{ Session 0: } \\
\hline $\begin{array}{l}\text { Activity: } \\
\text { Time: } \\
\text { Words: }\end{array}$ & \begin{tabular}{|l} 
Test 0 \\
$\infty$ \\
W \\
\end{tabular} & $\begin{array}{l}\text { Game } \\
10 \text { min } \\
\mathrm{W}_{1}\end{array}$ & \begin{tabular}{|l|} 
Test \\
$\infty$ \\
$\mathrm{W}_{1}$
\end{tabular} & $\begin{array}{l}\text { Flash } \\
10 \text { min } \\
\mathrm{W}_{2}\end{array}$ & \begin{tabular}{|l} 
Test \\
$\infty$ \\
$\mathrm{W}_{2}$ \\
\end{tabular} & \begin{tabular}{|l|} 
Memrise \\
$10 \mathrm{~min}$ \\
$\mathrm{~W}_{3}$
\end{tabular} & \begin{tabular}{|l} 
Test \\
$\infty$ \\
$\mathrm{W}_{3}$
\end{tabular} \\
\hline \multicolumn{8}{|c|}{ Session 1 (One week later): } \\
\hline $\begin{array}{l}\text { Activity: } \\
\text { Time: } \\
\text { Words: }\end{array}$ & \begin{tabular}{|l} 
Test 1 \\
$\infty$ \\
W \\
\end{tabular} & $\begin{array}{l}\text { Game } \\
10 \text { min } \\
\mathrm{W}_{1}\end{array}$ & \begin{tabular}{|l|} 
Test \\
$\infty$ \\
$\mathrm{W}_{1}$
\end{tabular} & \begin{tabular}{|l} 
Flash \\
10 min \\
$\mathrm{W}_{2}$
\end{tabular} & \begin{tabular}{|l} 
Test \\
$\infty$ \\
$\mathrm{W}_{2}$
\end{tabular} & \begin{tabular}{|l|} 
Memrise \\
$10 \mathrm{~min}$ \\
$\mathrm{~W}_{3}$
\end{tabular} & $\begin{array}{l}\text { Test } \\
\infty \\
\mathrm{W}_{3}\end{array}$ \\
\hline \multicolumn{8}{|c|}{ Session 2 (One week later): } \\
\hline $\begin{array}{l}\text { Activity: } \\
\text { Time: } \\
\text { Words: }\end{array}$ & \begin{tabular}{|l} 
Test 2 \\
$\infty$ \\
$\mathrm{W}$
\end{tabular} & & & & & & \\
\hline
\end{tabular}

Group A, for example, followed this schedule:

Whereas Group B had the schedule:

\begin{tabular}{|l|l|l|l|l|l|l|l|}
\hline \multicolumn{7}{|c|}{ Session 0: } \\
\hline Activity: & Test0 & Memrise & Test & Game & Test & Flash & Test \\
Time: & $\infty$ & 10 min & $\infty$ & 10 min & $\infty$ & 10 min & $\infty$ \\
Words: & $\mathrm{W}$ & $\mathrm{W}_{2}$ & $\mathrm{~W}_{2}$ & $\mathrm{~W}_{3}$ & $\mathrm{~W}_{3}$ & $\mathrm{~W}_{1}$ & $\mathrm{~W}_{1}$ \\
\hline \multicolumn{7}{|c|}{ Session 1 (One week later): } \\
\hline Activity: & Test1 & Memrise & Test & Game & Test & Flash & Test \\
Time: & $\infty$ & 10 min & $\infty$ & 10 min & $\infty$ & 10 min & $\infty$ \\
Words: & $\mathrm{W}$ & $\mathrm{W}_{2}$ & $\mathrm{~W}_{2}$ & $\mathrm{~W}_{3}$ & $\mathrm{~W}_{3}$ & $\mathrm{~W}_{1}$ & $\mathrm{~W}_{1}$ \\
\hline \multicolumn{7}{|c|}{ Session 2 (One week later): } \\
\hline Activity: & Test2 & & & & & & \\
Time: & $\infty$ & & & & \\
Words: & $\mathrm{W}$ & & & & & \\
\hline
\end{tabular}

During the tests following immediately after using a learning method, the participants were also asked to rate their enjoyment of the last method on a Likert-scale from 0 to 8 .

For each test, the participants were given a list of the English translations of the particular word group. They were then asked to write down the Italian translation. 
Test0 was given to participants before any learning occurred, to check whether prior knowledge exists. Test1 and Test 2 consisted of all 27 words for the user, but were broken down into three subtests for analysis of each method's performance.

All participants were students living in the Netherlands between the ages 18 and 27. None had studied Italian before.

During gameplay, the game also collected metrics about the player, recording for example how often each spell was chosen and the success rates for individual spells and words.

\section{RESULTS}

The results of the long term retention tests, which were administered one week after the last exercise, put the game slightly below flash cards and Memrise. After two weeks, participants remembered on average 6.08 words learned through the game, 6.25 words learned through flash cards and 6.58 words learned through Memrise (Figure 9).

Noticeably, the game scored better than flash cards after the first week with 2.83 words versus 2.75 words through flash cards; however, both these methods performed far below Memrise through which users remembered 3.75 words after the first week (Figure 10).

The game scored considerably higher in user enjoyment than the other methods, with 6.92 compared to 4.42 (Flash cards) and 4.55 (Memrise). Both other methods decreased in their rating from the first to the second week, whereas the game stayed consistent (Figure 11).

At the end of each session, users were also asked which method they would prefer using if they were to start learning a new language. The game was most often picked as first choice in both weeks. Memrise, which was voted as first choice by just one participant less than the game in the first week, was rated lower in the second week. Participants reported it to feel repetitive.

Additional results are attached as Appendix 1.

\section{CONCLUSIONS}

The prototype performed above expectations in regard of long term retention of words. The tests in the user study only assess the user's ability to correctly write the word, as that was the only aspect which could be compared across the three methods; however, the game also teaches the phonetics to the user at the same time.

Considering that the user spends a small fraction of gameplay on tasks which do not relate to the target language, it is possible that no version of the game could ever reach the efficiency of a direct learning application such as Memrise. Yet, as has been demonstrated, it can come very close to the same efficiency while being considerably more entertaining. Assuming that students would spend more time with a more enjoyable method of study, the game could prove more effective in teaching a language to the user, who might be less likely to drop their studies before reaching a conversational level.

Though it would appear that the enjoyment of the game stays high, while that of other methods declines over time, two sessions are hardly enough to make any conclusive statement. Participants reported enjoying beating the final

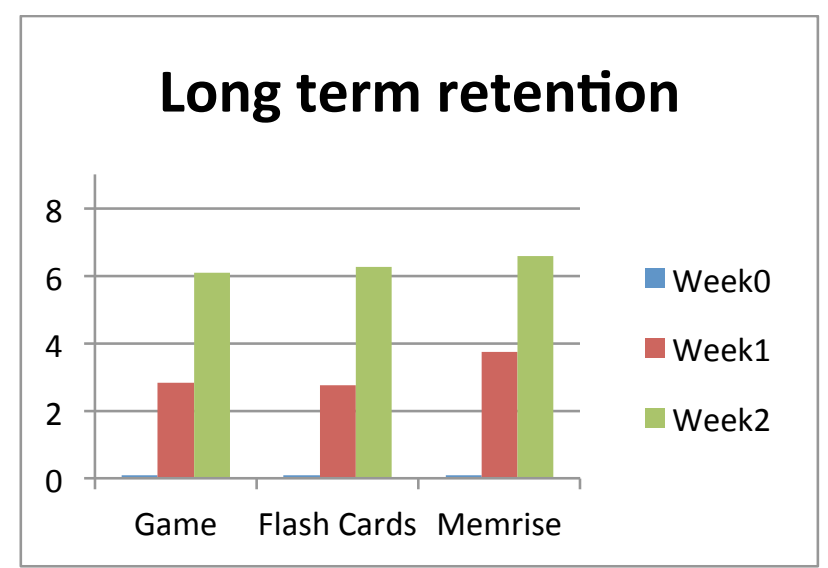

Figure 9. Results of the tests administered one week after the previous learning session.

\section{Enjoyment of Methods}

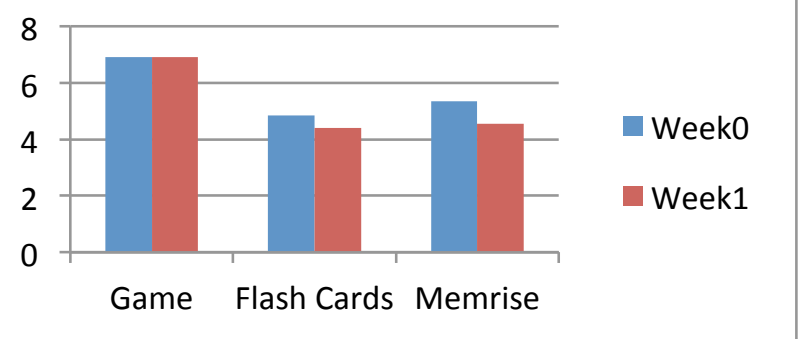

Figure 10. User reported enjoyment of the specific methods on a Likert scale from 0 to 8

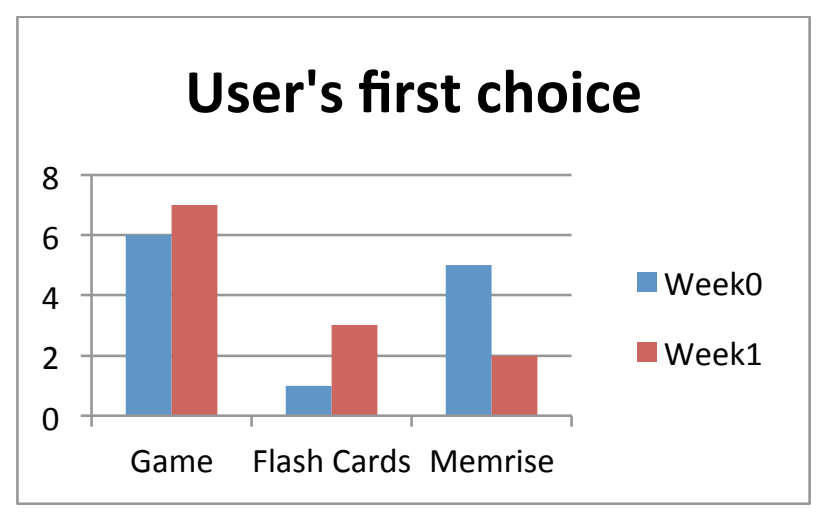

Figure 11. First choice of users

opponent in the game, which might result in the high ratings for the second week. The game may have to keep presenting novelty to keep the user engaged, which is a considerable effort over the entire time span of a language study.

A future prototype will have to prove whether the game can effectively teach grammar and the remaining aspects of lexemes to provide a complete language learning solution.

\section{ACKNOWLEDGMENT}

This paper was written as part of the International Game Architecture and Design curriculum at NHTV Breda, under supervision of Giuseppe Maggiore. 
PAPER

INCIDENTAL LEXICON ACQUISITION THROUGH PLAYFUL INTERACTION

\section{REFERENCES}

[1] K. B. Nielson, "SELF-STUDY WITH LANGUAGE LEARNING SOFTWARE IN THE WORKPLACE: WHAT HAPPENS?," Language Learning \& Technology, vol. 15, no. 3, pp. 110-129, 2011

[2] K. A. Noels, L. G. Pelletier, R. Clément and R. J. Vallerand, "Why are you learning a Second Language? Motivational Orientations and Self-Determination Theory," Why are you learning a Second Language? Motivational Orientations and Self-Determination Theory, pp. 57-85, 2000.

[3] A.-M. Masgoret and R. Gardner, "Attitudes, Motivation, and Second Language Learning: A Meta Analysis of Studies conducted by Gardner and Associates," Language Learning 53:1, pp. 123163, 2003.

[4] T. Susi, M. Johannesson and P. Backlund, "Serious Games - An Overview," University of Skövde, Sweden , Skövde, Sweden , 2007.

[5] S. Deterding, D. Dixon, R. Khaled and L. Nacke, "From Game Design Elements to Gamefulness: Defining "Gamification"," in CHI EA '11 CHI '11 Extended Abstracts on Human Factors in Computing System, New York, 2011.

[6] I. McGraw, B. Yoshimoto and S. Seneff, "Speech-enabled card games for incidental vocabulary acquisition in a foreign language," $11 \quad 04 \quad 2009 . \quad$ [Online]. Available: http:/groups.csail.mit.edu/sls/publications/2008/speechcomm08.p df.

[7] M. Carbonaro, M. Cutumisu, H. Duff, G. S., C. Onuczko, J. Schaeffer, A. Schumacher, J. Siegel, D. Szafron and K. Waugh, "Adapting a Commercial Role-Playing Game for Educational Computer Game Production," 2006. [Online]. Available: ttp://www.cs.cmu.edu/ waugh/publications/gameon06.pdf.

[8] R. Vesselinov and J. Grego, "Duolingo Effectiveness Study," December 2012. [Online]. Available: http://static.duolingo.com/s3/DuolingoReport_Final.pdf.

[9] J. H. Hulstijn, "Intentional and incidental second language vocabulary learning: A reappraisal of elaboration, rehearsal and automaticity," Cognition and Second Language Instruction, pp. 258286, 2001.
[10] R. Ellis, "Current Issues in the Teaching of Grammar: An SLA Perspective," TESOL QUARTERLY, Vol. 40, No. 1, pp. 83-107, 2006. http://dx.doi.org/10.2307/40264512

[11] L. Selinker, "Interlanguage," IRAL-International Review of Applied Linguistics in Language Teaching, 10(1-4), pp. 209-232, 1972.

[12] E. Tarone, "On the Variability of Interlanguage Systems," Applied linguistics, 4(2), pp. 142-164, 1983. http://dx.doi.org/10.1093/ applin/4.2.142

[13] L. \&. S. A. R. Shams, "Benefits of multisensory learning," Trends in cognitive sciences, 12(11), pp. 411-417, 2008. http://dx.doi.org/10.1016/j.tics.2008.07.006

[14] P. Pimsleur, "A Memory Schedule," drlodern Language Journal, Vol. 51, No. 2, pp. 73-75, 1967.

[15] S. Leitner, So lernt man lernen, Herder, 1974.

[16] B. Danet and T. Katriel, "No two alike: play and aesthetics in collecting," in Interpreting Objects and Collections, London, Routledge, 1994, pp. 220-239.

[17] W. J. M. Levelt, Speaking, Cambridge, MA: MIT, 1989, p. 188.

[18] E. Ushida, "The Role of Students' Attitudes and Motivation in Second Language Learning in Online Language Courses," CALICO Journal, vol. 23, no. 1, pp. 49-78, 2005.

[19] J. van Santen, L. Black, G. Cohen, A. Kain, E. Klabbers, T. Mishra, J. de Villiers and X. Niu, "Applications of Computer Generated Expressive Speech," 2003.

[20] S. Al Moubayed, "Prosodic Disambiguation in Spoken Systems Output," in Proceedings of Diaholmia'09: 2009 Workshop on the Semantics and Pragmatics of Dialogue, Stockholm, 2009.

[21] R. C. Gardner, "Correlation, Causation, Motivation, and Second Language," Department of Psychology; University of Western Ontario, 2000.

\section{AUTHOR}

L. W. Ansteeg is with the NHTV University, 4818CD Breda, Netherlands (e-mail: 112103@nhtv.nl).

Manuscript received 09 September 2014. Published as resubmitted by the author 21 February 2015. 